\title{
Antitobacco programs underfunded, WHO says
}

$\mathrm{T}$ obacco control programs remain "seriously underfunded" worldwide, despite increases in revenue-generating tobacco taxes, the World Health Organization (WHO) reveals in its third report on the global tobacco epidemic.

The big picture of the epidemic remains largely "unchanged," the WHO says, in part because of a lack of political will to finance antitobacco initiatives, although some countries have made progress to implement new control measures since 2009 (www.who .int/tobacco/global_report/2011/qanda /en/index.html).

Governments collect nearly US $\$ 133$ billion in tobacco tax revenue each year, but spend less than US $\$ 1$ billion on tobacco control, the WHO Report on the Global Tobacco Epidemic, 2011 reveals (http://whqlibdoc.who.int /publications/2011/9789240687813 _eng.pdf).

It's a disparity that Armando Peruga, program manager of the WHO's Tobacco Free Initiative, calls "basically ridiculous" and one that is particularly acute in lowand middle-income countries.

Tobacco tax revenues are 4304 times higher than tobacco control expenditures in low-income countries, compared to 1339 times higher in middleincome countries and 124 times higher in the wealthiest nations.

It's not for a lack of funds, either, the report argues, as "most countries have sufficient financial resources available to expand and strengthen [national tobacco control programs]."

Since 2008, 11 countries and one territory have increased taxes on tobacco products to the WHO-recommended minimum of $75 \%$ of the products' retail prices. At present, 26 countries and one territory in total, representing about $8 \%$ of the world's population, have set levies on tobacco at or above that minimum. A further 154 countries have set taxes on tobacco products at $25 \%-75 \%$ of their retail prices.

"There's still a belief out there that

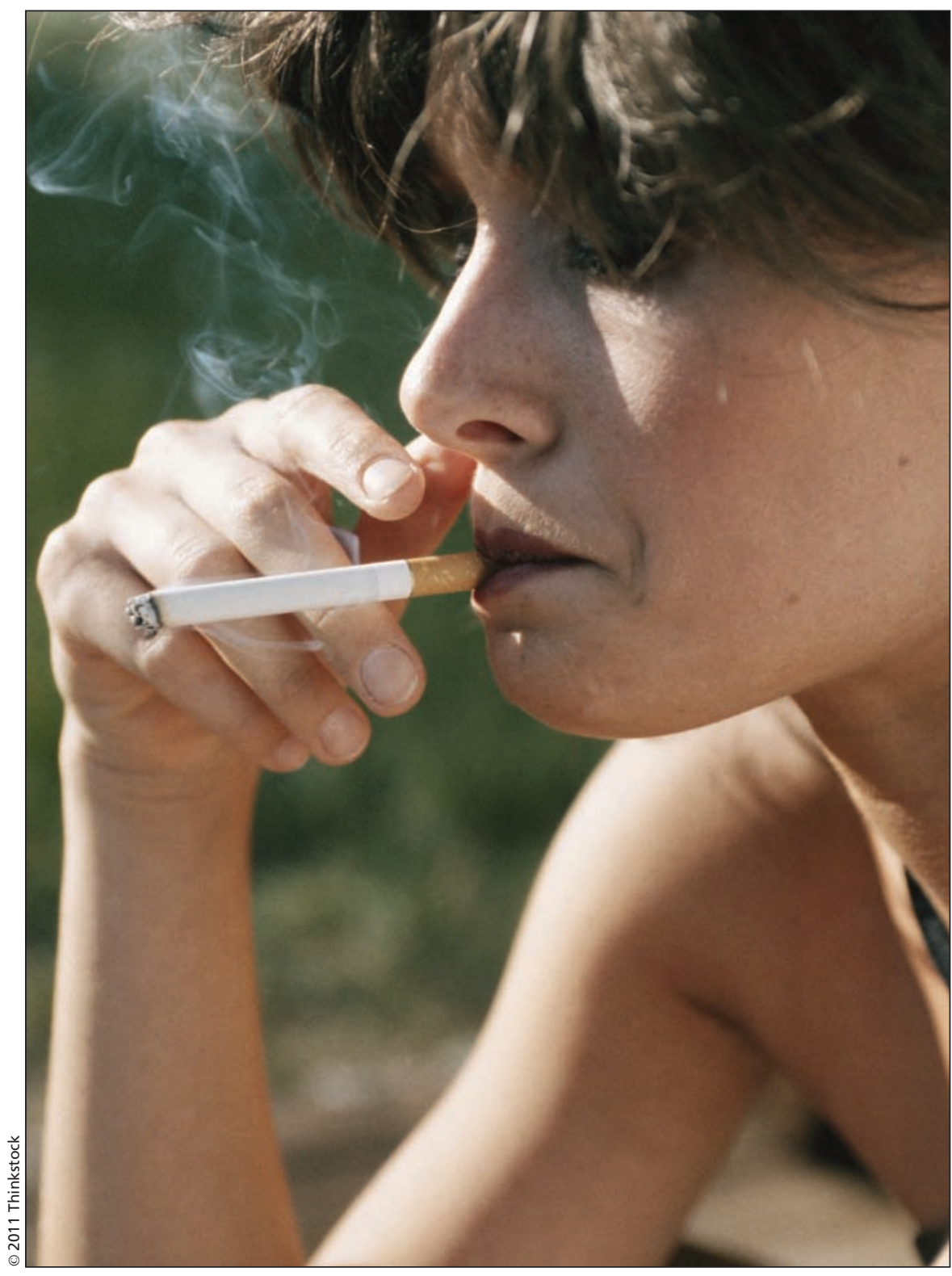

Governments around the world collect nearly US\$133 billion in tobacco tax revenue each year, but spend less than US\$1 billion on tobacco control, according to a new WHO report.

the tobacco epidemic is a problem of the rich countries or the rich people in poorer countries, and that's not true," says Peruga, explaining that some $80 \%$ of tobacco-related deaths occur in lowand middle-income countries.

"There's a link between tobacco use and poverty that we need to make apparent for countries, particularly lowincome countries, to really take on the epidemic as a social problem and economic problem, not just a health problem," he says.

It costs governments "almost nothing" to make workplaces, restaurants, bars and other indoor public places smoke-free, to enforce bans on tobacco advertising and sponsorship, or to require health warnings on tobacco products, the WHO argues — but only 
a minority of countries have implemented such measures to date.

"We still have not reached a critical mass of countries doing all they can and should, but we're seeing good progress in a handful of countries that are setting the pace for others," Peruga says. "We're beginning to see decreases in the prevalence of tobacco use, for example, in countries where we've not seen them in the past, such as Uruguay, India, Turkey and other middle-income countries."

Mandating graphic health warnings on tobacco products has been one of the most widely implemented interventions to date. More than 100 countries, representing over half of the global population, now have some kind of policy requiring warning labels on tobacco products. However, those policies only meet best practices in 19 countries, representing just $15 \%$ of the world's people.

The success of other interventions has been likewise tempered, according to the report.

Ninety-eight countries, representing about half of the global population, have legislated certain public places as smokefree environments, but only $11 \%$ of the world's people are actually covered by comprehensive smoke-free policies.

Comprehensive national health care services supporting smoking cessation are available in only 19 countries, representing $14 \%$ of the world's population.

Meanwhile, bans on tobacco advertising and sponsorship have the potential to decrease tobacco consumption by up to $16 \%$, according to WHO estimates, but only 19 countries, constituting $6 \%$ of the world's population, have introduced such strictures.
Tobacco-related illness kills nearly 6 million people each year, more than 600000 of whom are nonsmokers exposed to second-hand smoke. With tobacco consumption on the rise globally, the WHO warns that the annual death toll could climb to more than 8 million by 2030 .

"We are pleased that more and more people are being adequately warned about the dangers of tobacco use," WHO Assistant Director-General for Non-communicable Diseases and Mental Health Dr. Ala Alwan said in a press release (www.who.int/mediacentre /news/releases/2011/tobacco_20110707 /en/index.html). "At the same time, we can't be satisfied that the majority of countries are doing nothing or not enough." — Lauren Vogel, CMAJ

CMAJ 2011. DOI:10.1503/cmaj.109-3946 